\title{
The CS-US Interval Function in Rabbit Nictitating Membrane Response Conditioning: Single vs Multiple Trials Per Conditioning Session ${ }^{1}$
}

\author{
Charles F. Levinthal ${ }^{2}$ \\ University of Michigan
}

\begin{abstract}
The effect of varying trials per day conditions on the CS-US interval or interstimulus interval (ISI) function in rabbit nictitating membrane response conditioning was studied in two experiments. Experiment I showed that a 1250 -msec ISI was more effective than a $250-\mathrm{msec}$ ISI when there was 1 trial/day. Experiment 2 showed that as the number of trials per day decreased from 20 to 1 , the superiority of the $250-\mathrm{msec}$ ISI group over the 1250-msec ISI group declined, with a reversal at 1 trial/day. Results are interpreted in terms of the role of a hypothesized CS-elicited shortduration orienting response in CR performance.
\end{abstract}

The purpose of the present investigation was to determine the relationship between the trials per day parameter and the CS-US interval (interstimulus interval or ISI) function in the classical conditioning of the rabbit nictitating membrane response. Smith (1968) and Smith, Coleman, and Gormezano (1969), using 80-100 trials/day, have shown the ISI function for this response system to be concave-downward with optimum at $200-250 \mathrm{msec}$. Furthermore, ISI functions appear to be essentially unchanged with manipulations in (1) the type of US, i.e., airpuff (Schneiderman \& Gormezano, 1964) vs electric shock (Smith, Coleman, \& Gormezano, 1969), (2) US intensity (Smilh, 1968), and (3) CS duration, i.e., delay vs trace conditioning procedures (Schneiderman, 1966).

${ }^{1}$ This report is based upon a dissertation submitted to the Graduate School of the University of Michigan in partial fulfillment of the requirements for the Ph.D. degree. The author thanks James D. Papsdorf and Edward L. Walker for their support and critical reading of the manuscript. The research was supported by a graduate fellowship to the author from the National Science Foundation and, in part, by grants to James D. Papsdorf from the Office of Research Administration, University of Michigan.

${ }^{2}$ Requests for reprints should be sent to Charles F. Levinthal, Department of Psychology, Hofstra University, Hempstead, New York 11550. 
Salafia and Terry (1971), however, have recently demonstrated a marked convergence in the efficiency of 250 - and 1000 -msec ISIs in supporting $\mathrm{CR}$ acquisition as the number of trials per day is decreased from 120 to 5. Moreover, Levinthal and Papsdorf (1970) have shown that with 1 trial/day a substantial level of conditioning can be obtained and that a 1250 -msec ISI is more effective than a $250-\mathrm{msec}$ ISI. Since the latter results were a marked departure from earlier data on ISI functions, further investigations appeared warranted.

\section{GENERAL METHOD}

\section{Subjects}

One hundred and four male albino rabbits, 110 days old on delivery, were obtained from Johnson's Rabbitry (Coldwater, MI). All subjects were maintained by ad lib. access to food (Purina Rabbit Chow) and water.

\section{Procedure}

Subjects were prepared by tying a small nylon loop into the nictitating membrane of the right eye under local anesthesia (0.5\% Ophthaine solution). Each animal was placed in a Plexiglas restraining box having an adjustable back plate, head yoke, and foam rubber-padded ear clamp, which held the animal relatively immobile. During this habituation period, as in the experimental session, tailor hooks that served to retract the eyelids and expose the nictitating membrane, as well as deliver the shock US, were fastened by adjustable Vclcro straps to the supcrior and inferior lids of the right eye. The duration of the habituation period was determined so as to approximate the length of time the subject was to spend in the experimental setting on subsequent training sessions.

Subjects were placed in squads of four on a platform in a soundattenuated room, separated from the experimenter, programming equipment, and recording instruments, but could be readily observed at all times through a one-way window.

\section{Apparatus}

Movements of the nictitating membrane across the eye were monitored by a photoelectric transducer mounted on the rabbit's head by means of a muzzlelike assembly. The transducer was mechanically coupled to a nylon loop in the membrane by a thread to a counter-weighted lever on the shaft of the transducer. Variations in output voltage from the transducer were recorded by an ink-writing Beckman Type $\mathrm{R}$ Dynograph at a paper speed of $50 \mathrm{~mm} / \mathrm{sec}$. Conditioned responses were de- 
fined as movements of the membrane resulting in a minimal 1-mm deflection of the recording pen, occurring 50 msec after CS onset but with latencies shorter than the specified ISI.

The CS was a $93-\mathrm{dB}$ (SPL) $1000-\mathrm{Hz}$ tone and the US was a $60-\mathrm{Hz}$ 2.5-mA electric current, delivered across the eyelids through the tailor hooks. For those subjects receiving paired CS-US trials, the US overlapped the last 100 msec of CS presentation. In Experiment 1, the enclosure was kept essentially silent. In Experiment 2, there was a continuous $70-\mathrm{dB}$ white-noise background throughout training sessions.

\section{EXPERIMENT 1}

The substantial level of conditioning with 1 trial/day in the Levinthal and Papsdorf (1970) study could have been a result of an unusually high spontaneous nictitating membrane response rate present in the early period of confinement in the experimental setting. The superiority of the 1250-msec group could have been due to the increased interval during which a spontaneous response might occur. In view of these arguments, Experiment 1 sought to replicate the finding with the addition of groups receiving unpaired $C S$ and US presentations.

\section{Method}

Eight rabbits were randomly assigned to each of four experimental groups. Two groups received on each training day a single US presentation followed $30 \mathrm{sec}$ later by a single CS presentation which lasted either $350 \mathrm{msec}$ (250-unpaired group) or $1350 \mathrm{msec}$ (1250-unpaired group). Two other groups were trained with $1 \mathrm{CS}-\mathrm{US}$ trial/day at either a 250-msec (250-paired group) or 1250-msec (1250-paired group) ISI. All animals remained in the enclosure for $10 \mathrm{~min}$ at the end of each experimental session. Training was continued for 13 days for all animals.

\section{Results}

Figure 1 shows the mean percentage of responses emitted during the first 250 or $1250 \mathrm{msec}$ of the single CS presentation of each conditioning day in Experiment 1. For paired-trial groups these responses were classified as CRs; for unpaired-trial groups these responses were classified as spontaneous or pseudoconditioned responses.

The mean number of responses emitted during CS presentation over 13 days (trials) was 2.5 and 5.4 for the 250-paired and 1250-paired groups, respectively, and 0.4 and 1.5 for the 250-unpaired and 1250-unpaired groups, respectively.

An analysis of variance showed an acquisition superiority of the 1250msec ISI groups over the 250 -msec ISI groups $(F(1,28)=5.53 ; \eta<.01)$ 


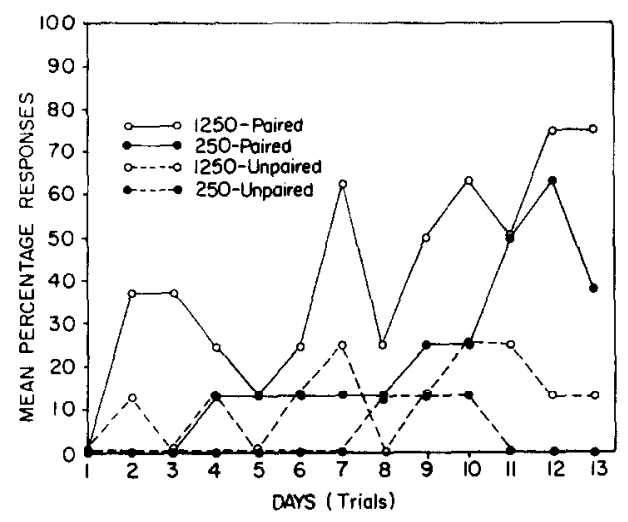

FIG. 1. Mean percentage of responses of groups trained at either a 250- or 1250-msec CS-US interval with either paired or unpaired event procedures.

and a superiority of paired-trial conditions over unpaired-trial conditions $(F(1,28)=12.43 ; p<.001)$, but no significant interaction $(F(1,28)=$ $1.02 ; p>.20)$.

The main effects and the absence of an interaction suggest that there is a nonassociative component of the 1250 -msec superiority in 1 trial/day conditioning, but that this component cannot by itself account for the 1250-msec superiority in paired-trial conditions.

\section{EXPERIMENT 2}

The primary importance of the next experiment was to document further the interaction of the trials per day parameter with the relative efficiency of two ISI values in CR acquisition. Salafia and Terry (1971), who studied ISI functions for groups having 5 to 120 trials/day, did not sample the lower limit of the trials per day dimension. Consequently, ISI functions with training schedules of 1,5 , or 20 trials/day were explored.

A secondary interest lay in the suggestion that the superiority of a 1250-msec ISI in the 1 trial/day schedule could be a result of an uneven distribution of CRs within sessions. If the 1250-msec ISI conditions produced CRs earlier in the session than, say, the 250-msec ISI level, then one would be able to see a general 1250 -msec ISI superiority over all trials per day $(1,5$, or 20$)$ procedures by merely recording the first trial of each session, no matter what its length.

\section{Method}

Seventy-two subjects were randomly distributed over six experimental groups. One animal died of a gastrointestinal infection, leaving unequal 
numbers in the experimental conditions. This was remedied for statistical analyses by random removal of one subject from each of the remaining cells, leaving 66 subjects, 11 per cell. Two ISI values ( 250 or $1250 \mathrm{msec}$ ) were orthogonal to three trials per day values $(1,5$, or 20 trials/day) in a $2 \times 3$ design. For multiple trial per day groups, the intertrial interval was $60 \mathrm{sec}$. All Ss remained in the enclosure for $10 \mathrm{~min}$ at the end of each experimental session. Conditioning sessions were continued for 13 days or until a criterion performance of $95 \%$ or more on two successive days was reached. Data for sessions subsequent to a subject's reaching criterion were extrapolated from asymptotic levels for analysis purposes.

\section{Results}

Figure 2 shows the mean percentage of CRs on each of 13 conditioning sessions for the six groups in Experiment 2.

An analysis of variance showed that $C R$ acquisition over conditioning sessions increased with the number of trials per day $(F(2,60)=59.9$, $p<.01)$ and that this relationship interacted with the ISI $(F(2,60)=$ $5.9, p<.01)$, although there was no significant ISI main effect $(F(1,60)=2.9, p>.05)$. There were, in addition, significant trials per day $\times$ sessions $(F(24,720)=7.7, p<.01)$, ISI $\times$ sessions $(F(12,720)=$ $4.2, p<.01)$, and trials per day $\times$ ISI $\times$ sessions $(F(24,720)=3.3, p<$ $.01)$ differences. If one were to assume the most extreme violations of homogeneity of covariance and adopt a conservative test for the repeatedmeasures interactions (Myers, 1967, pp. 161-162), all effects but the trials per day $\times$ ISI $\times$ sessions effect would still exceed the .05 level of statistical significance.

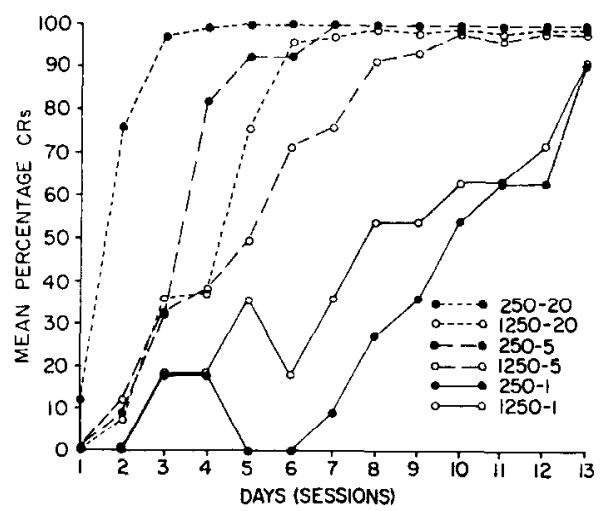

Fig. 2. Mean percentage of CRs of groups trained at either a 250 - or $1250-$ msec CS-US interval with either 1,5 , or 20 trials per day. 
The results corroborate the findings of Levinthal and Papsdorf (1970) and the data of Experiment 1 and, in addition, complement the observations of Salafia and Terry (1971) that the superiority of the 250-msec ISI groups diminishes as there are fewer trials on each daily session. Indeed, when there is 1 trial/day, the 250 -msec ISI superiority disappears.

With respect to the trials per day dimension alone, it should be pointed out that the superiority of the 20 trials/day groups over the others, as indicated in Figure 2, is dependent on measuring response probability over a number of daily sessions. If one observes, however, response probability over a number of trials, a totally different picture emerges. Now it is the 1 trial/day groups that are seen as the most rapid conditioners. Over the first 10 trials, for example, the 250-1 and 1250-1 groups emitted 18 and 33 CRs, respectively, while none of the others emitted more than 7 . The advantage of distributed practice on performance during the minimal number of trials in this experiment is similar to the effect seen in studies concerning motor skill and verbal learning (Underwood, 1961).

Mean CR percentages on the first trial of each daily session were $86 \%$ and $76 \%$ for the $250-20$ and $1250-20$ groups, respectively, $74 \%$ and $68 \%$ for the 250-5 and 1250-5 groups, respectively, and $29 \%$ and $41 \%$ for the 250-1 and 1250-1 groups, respectively.

The ordinal relationships between the three pairs of ISI groups in Figure 2 are maintained even when one is concerned only with the first trial of each session. Consequently, the superiority of the 1250 -msec ISI group with 1 trial/day cannot be attributed to a possible bias of longISI groups toward emitting CRs early within each session.

\section{DISCUSSION}

Experiments 1 and 2 confirmed the validity of the 1 trial/day ISI relationships as being due to genuine conditioning processes rather than procedural artifacts. The results of the two experiments demonstrate a strong and systematic relationship between the form of the ISI function and the trials per day parameter, namely, that the optimal ISI for singlecue conditioning shifts toward longer intervals as the number of CS-US trials per day is decreased.

Recent investigations have uncovered task difficulty as another experimental variable that affects the ISI function. Frey (1969) has shown that differential conditioning of the rabbit eyelid response has a longer optimal ISI than that observed in simple conditioning, when cue discrimination is made difficult. In a within-subjects design, with one CS associated with a 500-msec ISI and another CS with a 1200-msec 
ISI, Frey (1970) has subsequently found a greater conditioned eyelid response probability with the 1200 -msec cue. With one CS and two ISI values, response latencies are prolonged so as to produce more CRs during 1200-msec ISI trials than during 500-msec ISI trials.

Influence of the intertrial interval (ITI) variable on the ISI function for rabbits is less clear. Mis, Andrews, and Salafia (1970) have found recently that a $300-\mathrm{msec}$ ISI is more effective in conditioned nictitating membrane response acquisition than a 1000 -msec ISI when a 1-min ITI is used, but that there is little difference between these ISI groups with a 5-min ITI. Yet, Frey and Ross (1968) reported substantial ISI differences with a 5-min ITI in conditioned eyelid response acquisition. Moreover, Frey and Ross (1969) reported an absence of ISI $\times$ ITI interaction in a later study of conditioned eyelid response acquisition. The inconsistency in the data on ITI effects could be due to a difference in the response systems studied or in the particular trials per day value adopted. Mis et al. (1970) employed 15 trials/day, whereas Frey and Ross employed 50 trials/day in their 1968 study and 120 trials/day in their 1969 study. In any case, the generality of an ISI $\times$ ITI interaction can be questioned until further work is done.

One may tentatively conclude that when the number of trials per day decrease, or when experimental task demands increase, the effect is to shift the optimal ISI to longer intervals. Since formerly optimal ISIs lose their effectiveness to support conditioning, Frey (1970) has proposed a short-duration "response inhibition accompanying information processing" (RIAIP) to account for his results. In another approach, Levinthal and Papsdorf (1970), noting the parallelism between those variables causing a shift of the optimal ISI and those resulting in changes in the habituation of an orienting response (OR), have suggested that there exists during initial trials a CS-elicited short-duration OR reacting to situational complexity in the same way as RIAIP and acting in a manner antagonistic to the performance of the $\mathrm{CR}$, during the first few hundred msec after CS onset. The OR in question would appear in the rabbit as one of a constellation of responses (EEG desynchronization, cardiac deceleration, headturning, etc.) to sudden, novel environmental changes (Lynn, 1966). Interference from an OR would be seen predominantly in short ISI groups, where OR and CR latencies would coincide. Subjects in longer ISI groups would be less strongly affected, since at the point of CR occurrence the magnitude of the short-duration OR would have diminished. Conditioning procedures using multiple trials per day schedules or simple conditioning tasks would serve to habituate the OR rapidly, and interference effects would not be evident. However, as the conditioning procedures serve to retard OR habituation, OR-CR antago- 
nism would persist and shifts in the optimal ISI to longer intervals would be seen.

While the CR, as operationally defined, has been described as being topographically similar to the OR in the galvanic skin response (Badia \& Defran, 1969) and cardiac response (Wood \& Obrist, 1964; Wilson, 1969) systems, evidence of orienting responses in other systems suggest an antagonistic relationship to CRs, as described above. ORs in the opposite direction from CRs have been observed by Siegel (1972) in the eyelid response system, by Deaux (personal communication, 1970) in the retractor bulbi response system, and by Salafia (personal communication, 1971) in the nictitating membrane response system. All three of these systems have been suggested to be closely associated anatomically and functionally (Deaux \& Gormezano, 1963; Last, 1961).

While changes in ISI relationships can be accounted for by the action of an antagonistic OR upon CR performance, one must also account for the overall superiority of 1 trial/day groups with regard to the number of trials to criterial CR performance. One may draw on the concepts of reactive inhibition (IIull, 1952) or memory consolidation (McGaugh, 1966) to explain this relationship. An alternative account, however, can be proposed in terms of the attentional assistance, which the OR provides in the informational processing of external events. Those procedures that increase the probability of OR occurrence during CS-US trials may add in the coding of the CS-US contingency, from which CR performance is later derived.

\section{REFERENCES}

Badia, P., \& Defran, R. H. Orienting responses and GSR conditioning: a dilemma. Psychological Review, 1970, 77, 171-181.

Deaux, E. Personal communication, 1970.

Deaux, E., \& Gonmrzano, I. Fyehall retraction: acquisition and extinction in albino rabbit. Science, 1963, 141, 630-631.

Frey, P. W. Differential rabbit eyelid conditioning as a function of age, ISI, and cue similarity. Journal of Experimental Psychology, 1969, 81, 326-333.

FREY, P. W. Within-subject analysis of the CS-US interval in rabbit eyelid conditioning. Learning and Motivation, 1970, 1, 337-345.

Frey, P. W., \& Ross, L. E. Classical conditioning of the rabbit eyelid response as a function of the interstimulus interval. Journal of Comparative and Physiological Psychology, 1968, 65, 246-250.

Frey, P. W., \& Ross, L. E. Rabbit eyelid conditioning: effects of age, interstimulus interval, and intertrial interval. Developmental Psychobiology, 1969, 1, 276-279.

Hull, C. L. A behavior system. New Haven: Yale University Press, 1952.

LAst, R. J. Wolff's anatomy of the eye and orbit. Philadelphia: Saunders, 1961.

Levinthal, C. F., \& Papsdorf, J. D. The classically conditioned nictitating membrane response: The ISI function with one trial per day. Psychonomic Science, $1970,21,296-297$. 
LyNN, R. Attention, arousal and the orientation reaction. Oxford: Pergamon Press, 1966.

McGaugh, J. L. Time-dependent processes in memory storage. Science, 1966, 153, $1351-1358$.

Mis, F. W., Andrews, J. G., \& Salafia, W. R. Conditioning of the rabbit nictitating membrane response: ISI by ITI interaction. Psychonomic Science, 1970, $20,57-58$.

Myers, J. L. Fundamentals of experimental design. Boston: Allyn and Bacon, 1966.

Salafia, W. R. Personal communication, 1971.

Salafia, W. R., \& Terry, W. S. Conditioning of the rabbit nictitating membrane response as a function of number of trials per day. Paper read at the Easterr Psychol:rgical Association, New York, April, 1971.

Schnemerman, N. Interstimulus interval function of the nictitating membrane respon e of the rabbit under delay vs trace conditioning. Journal of Comparative and Physiological Psychology, 1966, 62, 397-402.

Schneiderman, N., \& Gormezano, I. Conditioning of the nictitating membrane of the rabbit as a function of CS-US interval. Journal of Comparative and Physiological Psychology, 1964, 57, 188-195.

SIEGEL, S. Latent inhibition and eyelid conditioning. In A. H. Black and W. F. Prukasy (Eds.), Classical conditioning II: Current theory and research. New York: Appleton-Century-Crofts, 1972. Pp. 231-247.

Sмiтh, M. C. CS-US interval and US intensity in classical conditioning of the rabbit's nictitating membrane response. Journal of Comparative and Physiological Psychology, 1968, 66, 679-687.

Smith, M. C., Coleman, S. R., \& Gormezano, I. Classical conditioning of the rabbit's nictitating membrane response at backward, simultaneous and forward CS-US intervals. Journal of Comparative and Physiological Psychology, 1969, $69,226-231$.

UNDERwooD, B. J. Ten years of massed practice on distributed practice. Psychological Review, 1961, 68, 229-247.

Wilson, R. S. Cardiac response: determinants of conditioning. Journal of Comparative and Physiological Psychology, 1969, 68, 1-23.

Woop, D. M., \& OBRist, P. A. Effects of controlled and uncontrolled respiration on conditioned heart rate response in humans. Journal of Experimental Psychology, $1964,68,221-229$.

(Received August 24, 1972) 